\title{
AROBON IN THE TREATMENT OF INFANTILE GASTRO-ENTERITIS : A CLINICAL TRIAL
}

BY

\author{
DAVID BEYNON, M.B., M.R.C.P., D.C.H. \\ (From the Hospital for Sick Children, Great Ormond Street, London)
}

In recent years a new therapeutic agent, ' arobon,' has been used in Spain, Switzerland, and other continental countries in the treatment of gastrointestinal disorders in infants. Arobon is a powder prepared from the bean of the carob tree, Ceratonia Siliqua, which grows abundantly on the shores of the Mediterranean.

During the Spanish Civil War Professor Ramos (1941) noticed that the children of the poor in Barcelona who ate large quantities of carob bean tended to constipation and also were less subject to gastro-enteritis than were the better fed. This led him to use the roasted pulp of the bean mixed with starch in the treatment of gastro-enteritis, and with this mixture he claimed good results. Similar trials were carried out by Rozalen Sales (1942) and by Anton (1943).

Following these results Messrs. Nestlé Ltd., in Switzerland, marketed a product of the carob bean mixed with starch and cocoa under the name of 'Arobon,' and this has since been used in several continental countries in the treatment of gastroenteritis and other intestinal disorders with much reported success.

\section{Composition and Properties}

Arobon is a brown coffee-coloured powder, made up of carob bean flour 85 per cent., starch 10 per cent., and cocoa 5 per cent. It has the following composition (Nestlé):

$\begin{array}{lrlr} & \% & & \% \\ \text { Fat } & 1 \cdot 5 & \text { Pectin } & 1 \cdot 5 \\ \text { Proteins } & 4 \cdot 5 & \text { Cellulose } & 6 \cdot 0 \\ \text { Soluble carbohydrates } & 45 \cdot 0 & \text { Lignin } & 21 \cdot 0 \\ \text { Starch } & 13 \cdot 5 & \text { Hemi-cellulose } & 21 \cdot 0 \\ \text { Mineral salts } & 3 \cdot 5 \text { Moisture } & 3 \cdot 5 \\ & 100 \mathrm{~g} . & =270 \text { calories } & \end{array}$

It is very simply prepared for use by adding the powder to boiling water in 5 per cent. or 10 per cent. strength and adding a saccharine tablet to sweeten. This makes a thin suspension very similar to broth in consistency with a taste resembling cocoa.

The action of arobon in gastro-enteritis is due to its high powers of adsorption and also perhaps to mild astringent properties. By virtue of its pectin and lignin content it is said to adsorb fluid and toxic substances in the intestinal tract, and also by the bulky bolus so formed to slow down intestinal peristalsis (Martin du Pan, 1945a). Pectin forms the basis of the apple diet treatment which has been extensively used in gastro-enteritis, and lignin is an allied substance with much greater adsorptive powers. Martin du Pan carried out several experiments on the adsorptive powers of arobon and found that a 5 per cent. suspension in an 8 per cent. solution of proteins adsorbed 30 per cent. of the proteins.

Arobon given by mouth in 5 per cent. or 10 per cent. strength changes the character of the stools within forty-eight hours; they become homogeneous, dark brown in colour, and paste-like in consistency.

\section{Previous Clinical Trials}

Various workers in Switzerland and France have reported trials of arobon for gastro-enteritis in infants and older children. The method of its use has been roughly the same in all cases. Arobon in water only, in 5 per cent. or 10 per cent. suspension, is given by mouth for the first twenty-four to fortyeight hours, followed by the slow addition of some form of milk food in slowly increasing quantities. Most workers employed intravenous infusion as well when necessary and also chemotherapy in the control of parenteral infection. The arobon is continued for about ten days, by which time the infant is on full strength feeds, and the arobon is then stopped. An acidified milk, such as 'Eledon' (Nestlé) was often used in the re-establishment of feeds.

From Switzerland, Martin du Pan (1945b) reports its use on fifty-nine cases of varying severity of gastro-enteritis and on six cases of coeliac disease. All his cases were over ten months of age, and he claimed very good results. In twenty cases of gastroenteritis in which he analyses results in comparison with twenty similar cases treated with apple diet, the stools on arobon became ' normal' in an average of 2.25 days, and complete cure was effected in an average of 3.6 days, while in the control series on apple diet the figures were 4.7 and 6.2 days respectively.

Rivier (1946) treated one hundred infants under six months of age with good results. He concludes: - The introduction of carob flour to the dietetics of small infants represents a decided step forward. 
TABLE 1

CASES TREATED WITH AROBON

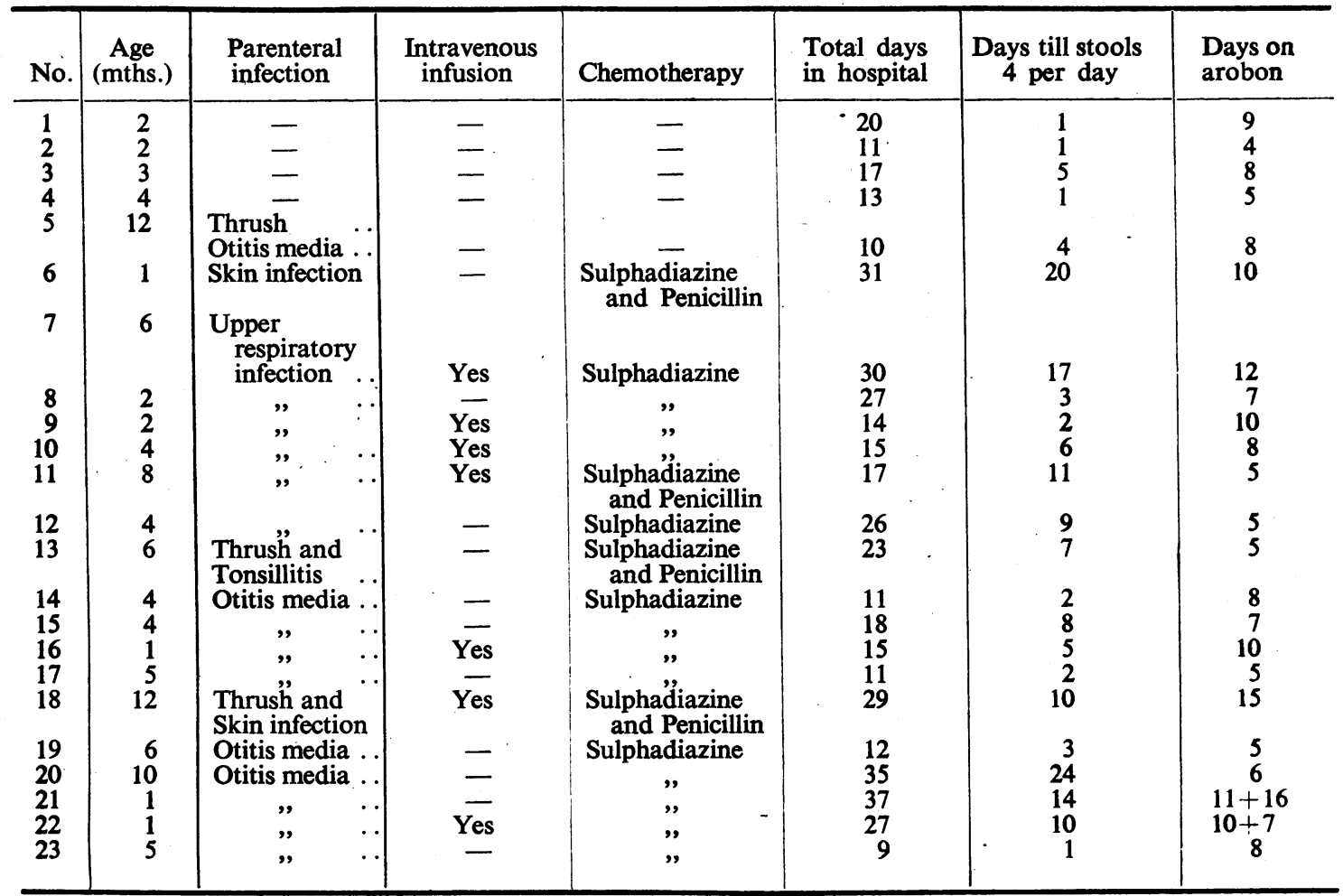

Results are especially striking in cases of acute gastro-enteritis'. He observes that arobon was not always well tolerated and was sometimes vomited.

Similar good results were obtained by Neyroud (1946) on eighty-one cases of gastro-enteritis of various ages, and by Nicod (1947) on forty-six young infants; the latter author states: 'The diarrhoeic character of the stools disappears more rapidly with arobon, and improvement of the general condition is quicker and more constant '. Nicod also treated milder cases of intestinal upset by adding arobon to their usual feeds.

All these reports agree that arobon is most successful in cases of primary gastro-enteritis, but that its action in controlling the stools is much slower when parenteral infection is present.

Boussardon (1947) in France reports its use on sixty-eight infants between the ages of seventeen days and fourteen months. He divides his cases into three categories: simple primary gastro-enteritis, of which there were only four cases and in which arobon gave good results; thirty-eight cases with parenteral infection, in which he found that control of the primary infection was necessary before cure occurred; and severe cases with 'toxic syndrome', in which he concludes that arobon exerts no influence on the general condition but is a useful adjunct to other forms of treatment by its control of the stools. He considers that arobon is a valuable addition to the treatment of infantile gastroenteritis, and in general its use enables a quicker resumption of feeding.

\section{Present Trial}

In view of these favourable reports a clinical trial was instituted at the Hospital for Sick Children on infants admitted to the gastro-enteritis unit over a period of six months. The general standard method of treatment was continued, but arobon was added in alternate cases, the others serving as controls. The results obtained in the 'trial' and 'control' series were then compared.

The standard method of treatment consists of stopping all feeds by mouth for twenty-four hours and substituting half-strength Hartmann's solution either by mouth or intravenously according to the severity of the case. This is followed by a schedule of feeds of either breast milk or half cream dried milk without added sugar in slowly increasing quantity and strength. Any parenteral infection is controlled by chemotherapy, and blood biochemistry is closely followed and upsets corrected. 
TABLE 2.

CONTROL CASES

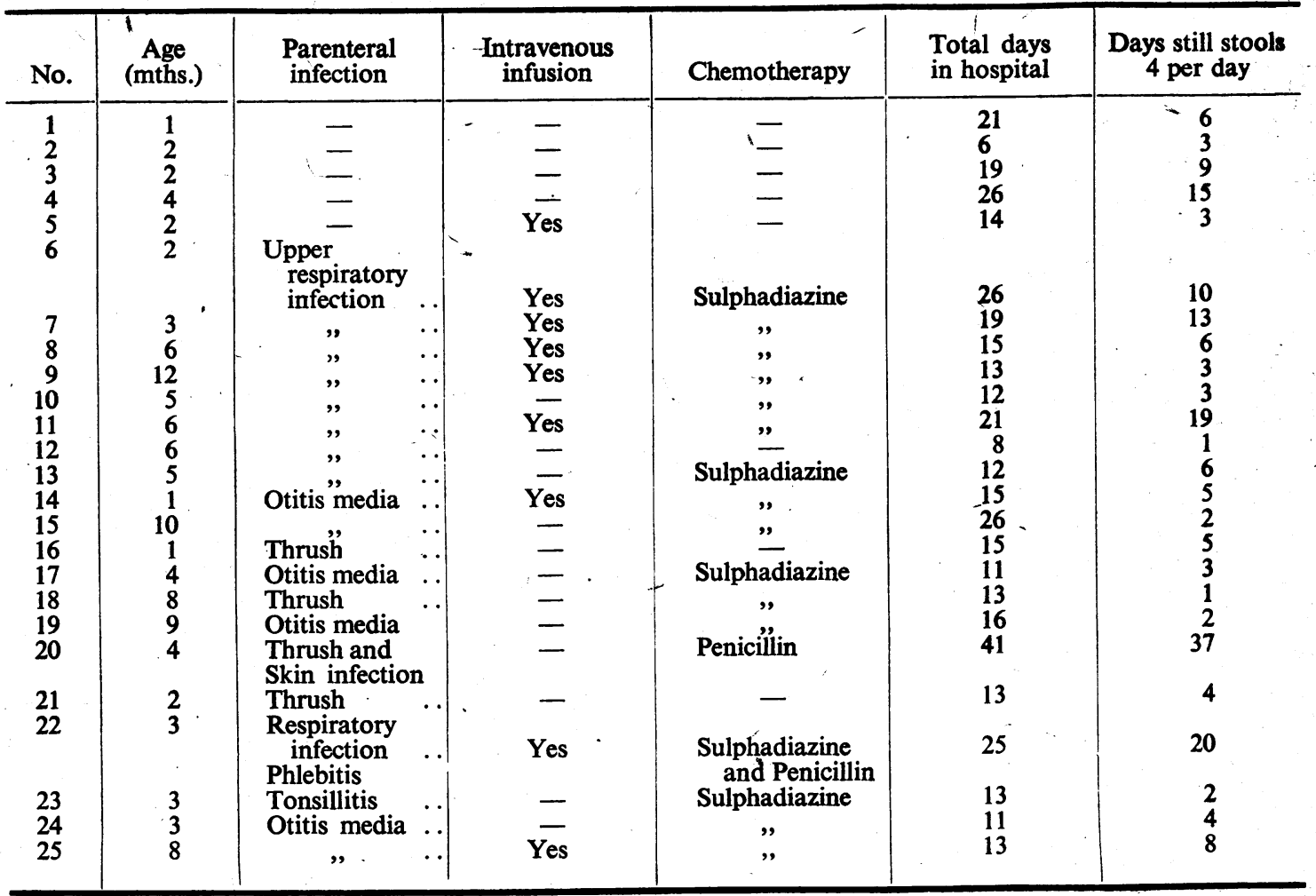

In the 'trial' series arobon in water only was given for the first twenty-four hours in place of Hartmann's solution. This was followed by the usual schedule of oral feeds, to which arobon was added. Seriously dehydrated patients were first put on intravenous infusion only for twenty-four hours before the arobon administration was started. Arobon was used in 5 per cent. strength for infarits up to six months of age and 10 per cent. strength over six months, and was continued for a varying time according to the response of the patient, the average time for all cases being nine days.

During the six months' period twenty-five cases in each series were treated and an analysis of their main features is given in tables 1 and 2. Two cases in the arobon series are not included; one infant developed pyaemia which needed prolonged treatment, another had to be taken off arobon after one day because of severe vomiting. It will be seen that the two series are roughly comparable: (a) in age group: the average age was 4.5 and 4.3 months respectively and the number of cases under three months of age in each series was eight; (b) in severity: seven and nine cases respectively needed intravenous infusion; (c) in incidence of parenteral infection: four and five cases respectively were primary gastro-enteritis.

\section{Discussion of Results}

These cases were in general severe grades of gastro-enteritis with general toxic manifestations and some degree of dehydration. The great majority of the cases had some form of parenteral infection which responded to chemotherapy; only a very few were of the primary type of enteral infection. This is in keeping with our usual experience in this unit.

Two figures are taken in an attempt to find an objective guide to the rapidity of cure: the total length of stay in hospital, and the number of days required to reduce the stools to four or less per day and to show an appreciable improvement in their consistency. The average figures dividing primary cases from those with parenteral infection, are given in table 3.

In the parenteral cases the addition of arobon showed no improvement in results. Recovery depended chiefly on the control of the primary infection.

In the few cases of primary gastro-enteritis it would seem that arobon quickly controlled the number of stools, and also the average length of stay in hospital was slightly reduced. It is difficult to draw conclusions from only four cases, but it was found that when the disease was severe the response in the general condition of the patient to 
TABLE 3

AVERAGE
CASES FIGURES
$\begin{gathered}\text { THOSE } \\ \text { INFECTION }\end{gathered}$ WIDING

\begin{tabular}{|c|c|c|}
\hline 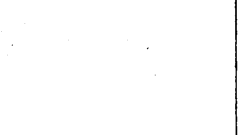 & $\begin{array}{c}\text { Average stay } \\
\text { in hospital } \\
\text { (in days) }\end{array}$ & $\begin{array}{l}\text { Average time } \\
\text { before stools } \\
\text { reduced to } 4 \text { per } \\
\text { day (in days) }\end{array}$ \\
\hline \multicolumn{3}{|c|}{ Arobon cases } \\
\hline $\begin{array}{c}\text { Enteral cases } \\
\text { Parenteral cases. } \\
\text { All cases }\end{array}$ & $\begin{array}{l}15 \cdot 2 \\
20 \\
19\end{array}$ & $\begin{array}{l}2 \\
8 \cdot 3 \\
7 \cdot 2\end{array}$ \\
\hline \multicolumn{3}{|c|}{ Control cases } \\
\hline $\begin{array}{c}\text { Enteral cases } \\
\text { Parenteral cases. } \\
\text { All cases }\end{array}$ & $\begin{array}{l}17 \cdot 2 \\
16 \cdot 9 \\
17\end{array}$ & $\begin{array}{l}7 \cdot 2 \\
7 \cdot 7 \\
7 \cdot 5\end{array}$ \\
\hline
\end{tabular}

restorative measures was no quicker in spite of the rapid reduction of stools. It was in the milder degree of disease that the response to arobon was most encouraging.

Our results do not confirm the promising reports of the previous trials, but the high incidence of parenteral infection found in our series may largely account for this. In our experience infantile gastroenteritis in its severer grades is a generalized disease, and any treatment directed to the alimentary tract alone has not been found to exert any appreciable effect.

Some other results of arobon administration were observed during the trial.

1. Older infants often dislike the taste and are reluctant to take arobon.

2. Arobon tends to aggravate any tendency to vomit. Three patients had to be taken off the treatment on the second, fifth, and sixth days respectively because of severe vomiting.

3. It is stated in the Swiss literature that arobon absorbs all the fluid portion of the stool. In our experience this is not strictly true. It certainly absorbs a large part of the fluid and all the faecal matter and is passed as a brown paste, but some fluid is often passed at the same time. This is colourless and odourless and is immediately absorbed into the napkin, so that its presence can be overlooked if its passage is not actually observed.

4. Addition of arobon does not prevent relapse. Four cases in the arobon series and two cases in the control series had a recrudescence of symptoms after a short period of improvement.

\section{Conclusions}

1. In cases of gastro-enteritis with parenteral infection, cure of the disease depends upon control of the primary infection and the addition of arobon exerts no appreciable effect.

2. In primary gastro-enteritis arobon can appreciably reduce the number of stools passed and in such cases may be useful as symptomatic treatment, but it is doubtful whether it speeds recovery in severe cases.

3. Arobon does not prevent relapse.

4. In the presence of severe vomiting it is not always tolerated.

5. It may be that arobon has a more useful place in the treatment of early or mild cases when its symptomatic action would serve more purpose.

\section{Summary}

A new therapeutic agent advocated in the treatment of gastro-enteritis is described. A short history of its discovery and of previous reports of its use are given, followed by a description of its trial on cases admitted to a gastro-enteritis unit over a period of six months. The conclusions drawn do not confirm previous reported results, but it is considered that further trials are indicated in primary gastro-enteritis as it might well prove useful in early cases of this type.

I am indebted to Dr. Bernard Schlesinger for his help in preparing this paper and for permission to publish these cases treated under his care, and also to Messrs. Nestlé Ltd. for their generous supply of arobon for the trial.

\section{REFERENCES}

Anton, L. (1943). Med. Espan., 10, 89.

Boussardon, H. (1947). Nourrisson, 35, 158.

Martin du Pan, R. (1945a). Galenica, 1, 11.

- (1945b). Schweiz. med. Wschr., 75, 763.

Neyroud, M. (1946). Ann. Paed., 166, 113.

Nicod, M. (1947). Praxis, 36, 105.

Ramos, R. (1941). Clin. y Lab., i.

Rivier, C. (1946). Praxis, 35, 652.

Rozalen Sales, M. (1942). Med. Espan., 8, 563. 